\title{
Effect of Nano-ZnO Particle Suspension on Growth of Mung (Vigna radiata) and Gram (Cicer arietinum) Seedlings Using Plant Agar Method
}

\author{
Pramod Mahajan, S. K. Dhoke, and A. S. Khanna \\ Department of Metallurgical Engineering and Material Science, Indian Institute of Technology Bombay, Mumbai, 400076, India
}

Correspondence should be addressed to S. K. Dhoke, shailesh_zeo@rediffmail.com

Received 23 March 2011; Accepted 9 June 2011

Academic Editor: Yoke Khin Yap

Copyright ( 2011 Pramod Mahajan et al. This is an open access article distributed under the Creative Commons Attribution License, which permits unrestricted use, distribution, and reproduction in any medium, provided the original work is properly cited.

\begin{abstract}
The present study demonstrates an effect of nano-ZnO particles on the growth of plant seedlings of mung (Vigna radiate) and gram (Cicer arietinum). The study was carried out in plant agar media to prevent precipitation of water-insoluble nanoparticles in the test units. Various concentrations of nano- $\mathrm{ZnO}$ particles in suspension form were introduced to the agar media, and their effect on the root and shoot growth of the seedlings was examined. The main experimental approach, using correlative light and scanning electron microscopy provided evidence of adsorption of nanoparticles on the root surface. Absorption of nanoparticles by seedlings root was also detected by inductive coupled plasma/atomic emission spectroscopy (ICP-AES). It was found that at certain optimum concentration, the seedlings displayed good growth over control, and beyond that, retardation in growth was observed.
\end{abstract}

\section{Introduction}

Nanotechnology is a versatile field and has found application in almost all existing fields of science. The use of nanoparticles in the growth of plants and for the control of plant diseases is a recent practice [1-5]. However, whether beneficial or harmful to plant growth is an unresolved issue $[6,7]$. Various studies had been carried out to understand the effect of nanoparticles on the growth of plants. For example, $\mathrm{Lu}$ et al. [8] studied the effect of mixtures of nano- $\mathrm{SiO}_{2}$ and nano- $\mathrm{TiO}_{2}$ on soybean seed. They found that the mixture of nanoparticles increases nitrate reductase in soybean increasing its germination and growth. Hong et al. $[9,10]$ and Yang et al. [11] reported that a proper concentration of nano- $\mathrm{TiO}_{2}$ was found to improve the growth of spinach by promoting photosynthesis and nitrogen metabolism. Canas et al. [12] found that nanofunctionalized carbon nanotubes enhanced root elongation in onion and cucumber.

Nano-ZnO has been widely used in industry for several decades. However, no study had been made on its potential use in agricultural. Zinc is one of the micronutrient of plants, and limited studies have been done on its beneficial effect on plant growth. However, its phytotoxicity has been reported
[13]. The Present study deals with the effect of nano$\mathrm{ZnO}$ particle suspension, as micro-nutrient on the growth of mung and gram seedlings at various concentrations by plant agar method [7]. The possible toxic effect at higher concentration was also studied. The concentration of nano$\mathrm{ZnO}$ particles in root was determined by inductively coupled plasma/atomic emission spectroscopy. The distribution of nano- $\mathrm{ZnO}$ particle and the architecture of root were studied using light microscopy and scanning electron microscopy.

\section{Materials and Methods}

2.1. Preparation of Nano-ZnO Particle Suspension. Nano$\mathrm{ZnO}$ particle (size $20 \mathrm{~nm}$ ), used for this study was synthesized in our laboratory. Particle size was characterized using transmission electron microscopy (TEM, Philips CM200 electron microscope). Nanoparticles were directly suspended in deionized water and were dispersed using mechanical stirrer and ultrasonicator $(100 \mathrm{~W}, 40 \mathrm{khz})$ for $30 \mathrm{~min}$. Nanoparticle suspensions of different concentration were prepared separately by weighing particles and dispersing them in deionized water. 
2.2. Seeds. Seeds of plant species mung (Vigna radiata) and gram (Cicer arietinum) were purchased locally. Seeds were kept in dry place in the dark under room temperature prior to use.

2.3. Germination of Seeds. Mung and gram seeds were sterilized in $5 \%$ sodium hypochlorite solution for $10 \mathrm{~min}$ to ensure surface sterility and were rinsed thoroughly with deionised water several times. Mung and Gram seeds were allowed to germinate in wet cotton, at a controlled temperature of $25 \pm 1{ }^{\circ} \mathrm{C}$ in the dark for 24 hours, respectively. The seeds were checked for germination and sprouted seeds were used for further study.

2.4. Plant Agar Method. The effect of nano- $\mathrm{ZnO}$ particle suspension on the growth of seedlings was conducted in Petri dish test unit $(87 \mathrm{~mm} \times 18 \mathrm{~mm})$. Each Petri dish containing $30 \mathrm{~mL}$ of dual agar culture media $(20 \mathrm{~mL}$ of $2.5 \%$ agar covered with $10 \mathrm{~mL}$ of $1 \%$ agar) were used in the test. To these Petri dish test units, specific concentrations of nano$\mathrm{ZnO}$ particles suspension were added $(0,10,20,50,100$, 500, 1000, and $2000 \mathrm{ppm}$ for mung seeds and 0, 1, 2, 5, $10,20,50,100,500,1000$, and $2000 \mathrm{ppm}$ for gram seeds). For preparing the test media, $20 \mathrm{~mL}$ of $2.5 \%$ agar solution was poured into a Petri dish test unit and immediately solidified in freezer to avoid the possible precipitation of nanoparticles. Again, $10 \mathrm{~mL}$ of $1 \%$ agar solution was poured evenly over $2.5 \%$ agar media. To each Petri dish test unit, 10 plant seedlings were gently placed above the surface of agar media. The test units were placed in incubator at a controlled temperature of $25 \pm 1^{\circ} \mathrm{C}$ in dark. For each concentration, three replicates were prepared and the test units were exposed for $60 \mathrm{hr}$. After exposure period, the seedlings were separated from agar media and their growth response was measured with ruler. Agar media without nano- $\mathrm{ZnO}$ particles were used as control. Based on our preliminary observations, the test units showing highest and lowest seedling growth for corresponding nano- $\mathrm{ZnO}$ concentrations with respect to control were selected for further studies.

2.5. Sample Preparation for Microscopy. For light microscopy, the root sample sections were taken manually and were observed under light microscope (Leica, DM500 B, Germany). For scanning electron microscopy, the control and nano- $\mathrm{ZnO}$ particle treated seedlings were cut to separate root and shoot. The roots were frozen in liquid nitrogen and then cut into smaller pieces with blunt knife. The pieces were freeze-dried overnight at $-30^{\circ} \mathrm{C}$ under vacuum (1525 torr) using freeze dry system (ALPHA1-2 LDplus, Germany). The morphology of roots was examined by scanning electron microscope, while quantitative elemental analysis for presence of nanoparticles was carried out with electron diffraction spectrum (SEM/EDS, Model no. S3400, Hitachi).

\subsection{Biomass Assay and Zinc Concentration Determination.} At the end of the experiment, seedlings were washed with deionised water. Roots and shoots were separated from seedlings for biomass determination. Initially, the fresh

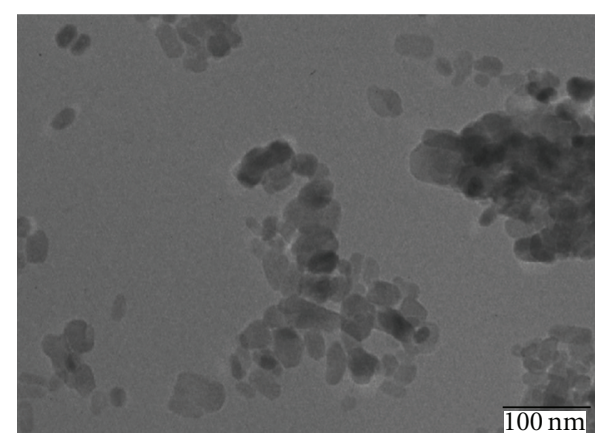

(a)

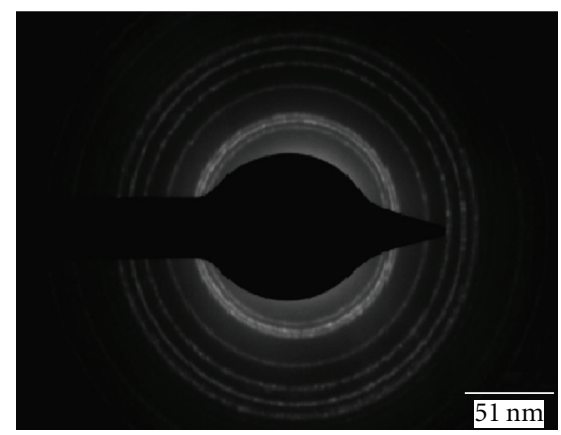

(b)

Figure 1: (a) TEM image of nano-ZnO Particles. (b) SAED pattern of nano-ZnO Particles.

weight of roots and shoots was measured, dried in oven at $70^{\circ} \mathrm{C}$ for $24 \mathrm{hr}$ and dry weights were recorded. $\mathrm{Zn}$ content in the root was also determined by inductively coupled plasma/ atomic emission spectroscopy (ICP-AES, Model Ultima, Jobin-Yvon Company, France) after $\mathrm{HNO}_{3}$ digestion of dry roots.

2.7. Statistical Analysis. The experiment was conducted in three replicates and the results were presented as the mean \pm SD (standard deviation). The statistical analysis of experimental data utilized Student's $t$-test. Each of the experimental value was compared to its corresponding reference. Statistical significance was accepted when the probability of result assuming the null hypothesis $(P)$ was less than 0.05 .

\section{Result and Discussion}

3.1. TEM Study of Nano-ZnO Particles. The transmission electron microscopy (TEM) image and selected area electron diffraction (SAED) pattern of $\mathrm{ZnO}$ particles are shown in Figures 1(a) and 1(b), respectively. The TEM micrographs indicated that the zinc oxide particles were monodispersed with a narrow size distribution and near spherical morphology. Analysis of particles in TEM monograph indicates hexagonal particles with the average size of $20 \mathrm{~nm}$. The SAED pattern shows that the rings are composed of dots suggesting the crystalline nature of $\mathrm{ZnO}$ particles.

3.2. Effect of Nano-ZnO Particles Suspension on Root and Shoot Growth. The dose response curves of nano- $\mathrm{ZnO}$ on 


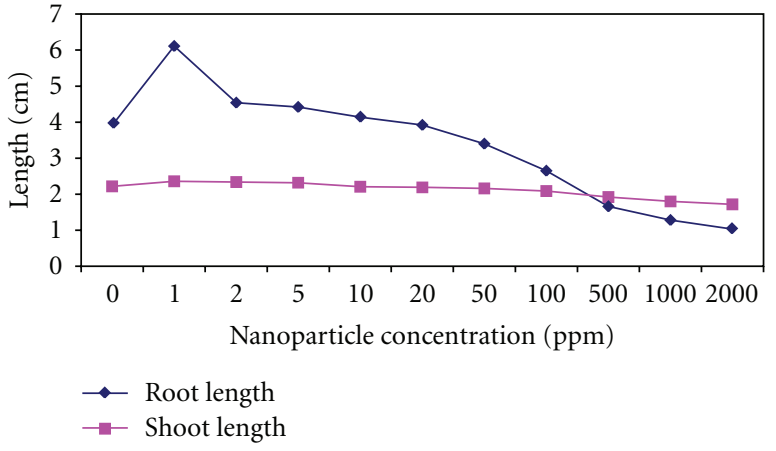

(a)

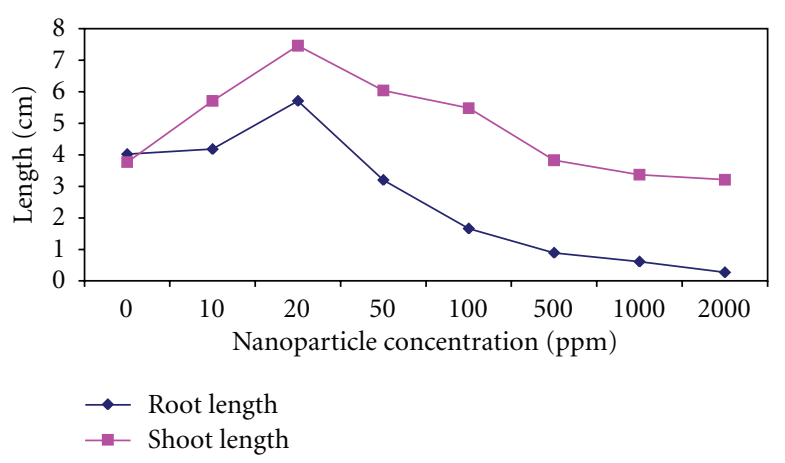

(b)

Figure 2: (a) Dose-response curves of nano- $\mathrm{ZnO}$ on root and shoot of mung seedlings. The values were given as mean \pm SD (standard deviation) of triplicate samples with 10 seeds each. (b) Dose response curves of nano- $\mathrm{ZnO}$ on root and shoot of (b) gram seedlings. The values were given as mean $\pm \mathrm{SD}$ (standard deviation) of triplicate samples with 10 seeds each.

root and shoot of mung and gram seedlings are shown in Figures 2(a) and 2(b), respectively. It was observe that with increase in nano- $\mathrm{ZnO}$ concentration, the root and shoot growth also increases. However, after certain concentration the growth of root and shoot was found to decline. For mung seedlings, the best growth response for root $(42.03 \%$, $P$ value 0.0498$)$ and shoot $(97.87 \%, P$ value 0.0444$)$ was observed at a concentration of $20 \mathrm{ppm}$ over control. At highest concentration, $2000 \mathrm{ppm}$ the retardation in root $\left(93.28 \%, P\right.$ value $\left.1.736 \times 10^{-14}\right)$ and shoot $(14.85 \%$, $P$ value $2.46 \times 10^{-11}$ ) growth of mung seedlings were observed over the control. Similarly, for gram seedlings, the dose of $1 \mathrm{ppm}$ promotes significant increase in root $\left(53.13 \%, P\right.$ value $\left.1.125 \times 10^{-7}\right)$ and shoot $(6.38 \%, P$ value 0.026) growth as compared to control. However, beyond this concentration retardation in growth of root and shoot was observed. At a dose of $2000 \mathrm{ppm}$, significant reduction in the root growth $\left(74.18 \%, P\right.$ value $\left.1.32 \times 10^{-10}\right)$ and shoot growth $(22.52 \%, P$ value 0.020$)$ was observed. The reduction in root and shoot growth at higher doses may be attributed to toxic level of nanoparticles. This is good evidence for demonstrating that mung and gram seedlings respond to added nanoparticles in a limited range, above which toxic levels are reached causing subsequent declines in growth.

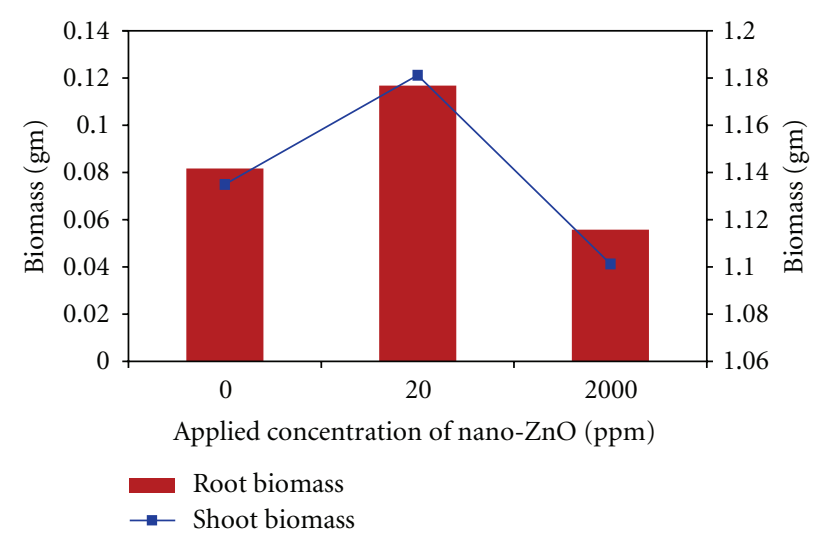

(a)

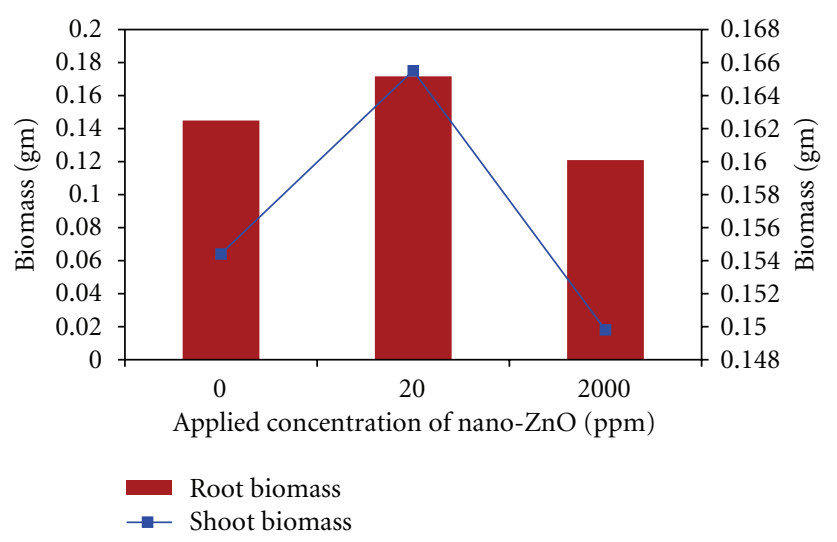

(b)

FIGURE 3: (a) Dry biomass of root and shoot of mung seedlings. (b) Dry biomass of root and shoot of gram seedlings.

3.3. Effect of Nano-ZnO Particles Suspension on Biomass. The graph of biomass estimated with respect to concentration of nanoparticles for mung and gram seedlings is shown in Figures 3(a) and 3(b), respectively. Root and shoot biomass production were found to be in accordance with the root and shoot length for corresponding nano- $\mathrm{ZnO}$ treatment. For nano- $\mathrm{ZnO}$ at $20 \mathrm{ppm}$ treatment, mung seedlings showed $40.89 \%$ increase the root biomass and $76.04 \%$ increase in shoot biomass over control. In case of gram seedlings at $1 \mathrm{ppm}$ treatment, $37.15 \%$ increase in root biomass and $26.61 \%$ increase in shoot biomass was observed. At the highest concentration of $2000 \mathrm{ppm}, 44.75 \%$ decrease of root biomass and $31.95 \%$ in shoot biomass for mung seedling was observed over control. While for gram seedlings, $32.25 \%$ decrease in root biomass and $52.84 \%$ decrease in shoot biomass were observed. The increase in biomass at certain concentration suggests the optimum dose limit for the growth of mung and gram seedlings. However, the decrease in biomass beyond this concentration suggests the toxic effect of nano- $\mathrm{ZnO}$ particles.

3.4. Elemental Determination. Table 1 shows the $\mathrm{Zn}$ content in the roots of mung and gram seedlings at optimum and highest concentration. It was observed that the $\mathrm{Zn}$ content of the roots in mung and gram increased significantly with the 


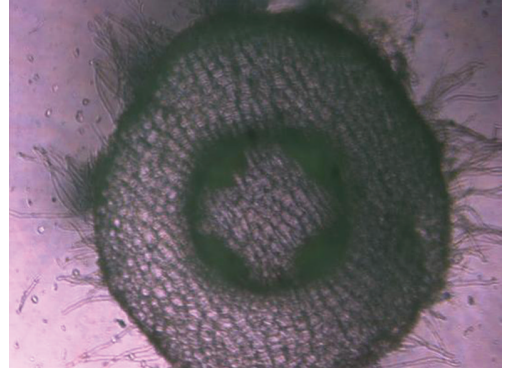

(a)

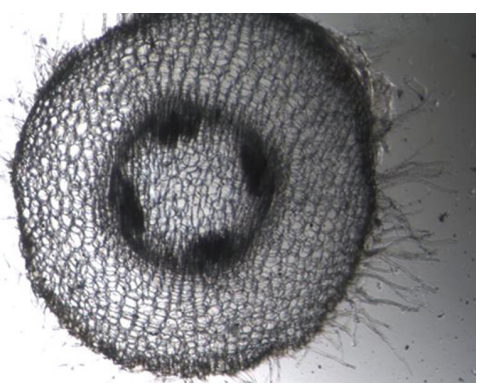

(b)

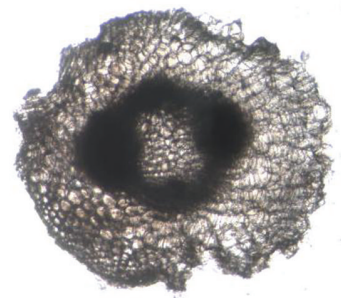

(c)

Figure 4: Transverse section of mung-seedling roots (a) control, (b) at $20 \mathrm{ppm}$, and (c) at $2000 \mathrm{ppm}$ of nano-ZnO treatment.

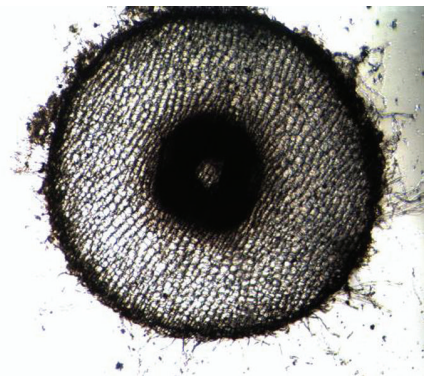

(a)

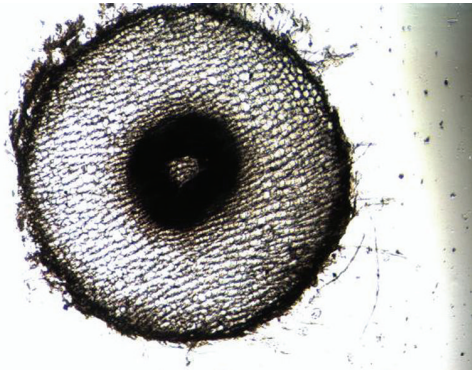

(b)

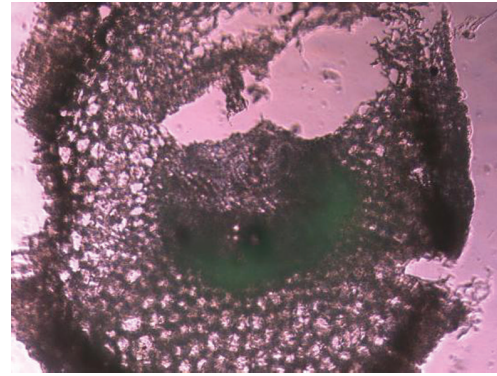

(c)

Figure 5: Transverse section of gram-seedling roots (a) control, (b) at $1 \mathrm{ppm}$, and (c) at $2000 \mathrm{ppm}$ of nano-ZnO treatment.

TABLE 1: Weight of zinc element in (a) mung and (b) gram seedling roots determined by ICP-AES.

(a)

\begin{tabular}{ll}
\hline $\begin{array}{l}\text { Concentration of nano-ZnO } \\
\text { added }(\mathrm{ppm})\end{array}$ & $\begin{array}{l}\text { Concentration of nano- } \mathrm{ZnO} \\
\text { determined by ICP-AES }(\mathrm{mg} / \mathrm{L})\end{array}$ \\
\hline 0 & 2.80 \\
20 & 12.17 \\
200 & 31.18 \\
\hline
\end{tabular}

(b)

\begin{tabular}{ll}
\hline $\begin{array}{l}\text { Concentration of nano-ZnO } \\
\text { added }(\mathrm{ppm})\end{array}$ & $\begin{array}{l}\text { Concentration of nano- } \mathrm{ZnO} \\
\text { determined by ICP-AES }(\mathrm{mg} / \mathrm{L})\end{array}$ \\
\hline 0 & 2.80 \\
1 & 12.17 \\
2000 & 31.18 \\
\hline
\end{tabular}

increase of nano- $\mathrm{ZnO}$ application. It indicates that the $\mathrm{ZnO}$ nanoparticles are absorbed and translocated in seedlings resulting in increase in $\mathrm{Zn}$ content at corresponding nano$\mathrm{ZnO}$ treatment.

3.5. Microscopic Analysis. The effect of $\mathrm{ZnO}$ nanoparticles to the mung and gram roots were further examined by light microscope. Figures 4 and 5 shows the transverse section of mung and gram roots, respectively. At a treatment of 20 ppm (Figure 4(b)) and 1 ppm (Figure 5(b)) concentration dose of nano- $\mathrm{ZnO}$ for mung and gram, respectively, the root developed very well with the usual three tissue system (epidermis, cortex, and vascular cylinder) as observed in control (Figures 4(a) and 5(a)). This indicates no adverse effect of nano- $\mathrm{ZnO}$ particles on the architecture of roots. However, the disruption of epidermis, cortex and vascular cylinder in both mung and gram roots (Figures 4(c) and 5(c)) was observed at higher concentration. The cortical cells were highly vacuolated and collapsed, while vascular cylinder was shrunk. The damage to the basic architecture of roots at higher concentration may be a direct reason for the growth inhibition in mung and gram seedlings [14].

Figures 6 and 7 shows the surface micrographs of roots of mung and gram seedlings, respectively. At a treatment of 20 ppm (Figure 6(b)) and 1 ppm (Figure 7(b)) concentration of nano-ZnO particles for mung and gram, respectively, no structural alteration on the root surface were observed when compared with respective control samples (Figures $6(\mathrm{a})$ and $7(\mathrm{a})$ ). However, structural alteration in root surface was observed for seedlings treated at higher concentrations. Damage to the epidermal layer of roots at higher concentration was evident from Figures 6(e) and 7(e). The adsorption and aggregation of nano- $\mathrm{ZnO}$ particles were observed on root surface of treated seedling, which was located and identified on the root surface by SEM-EDEX analysis (Figures 6(c), 6(d), 6(f), 6(g), 7(c), 7(d), 7(f), and 7(g)). 


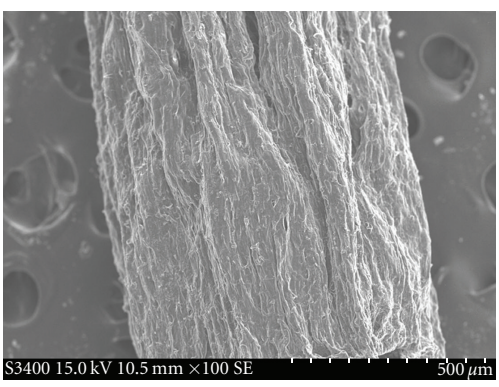

(a)

Full-scale counts: 1678

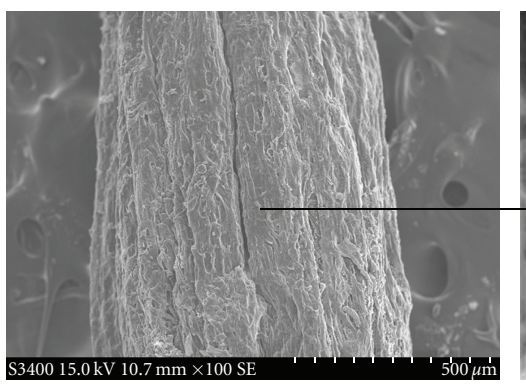

(b)

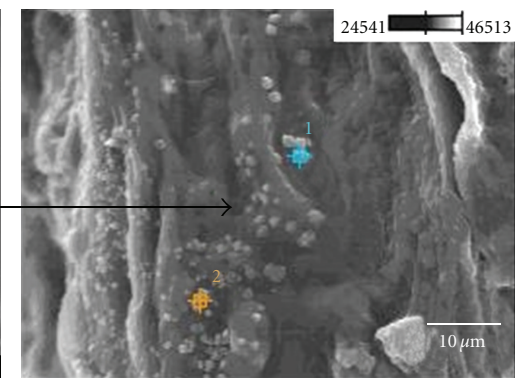

(c)

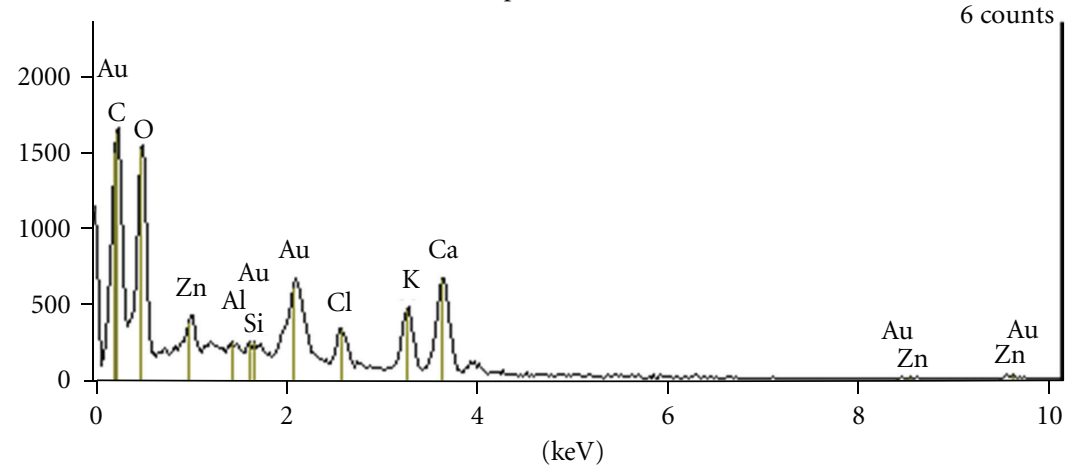

(d)

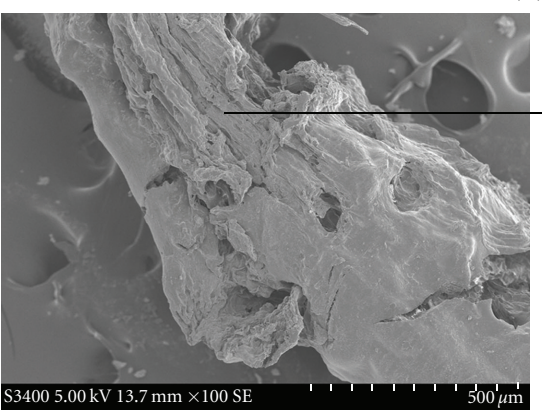

(e)

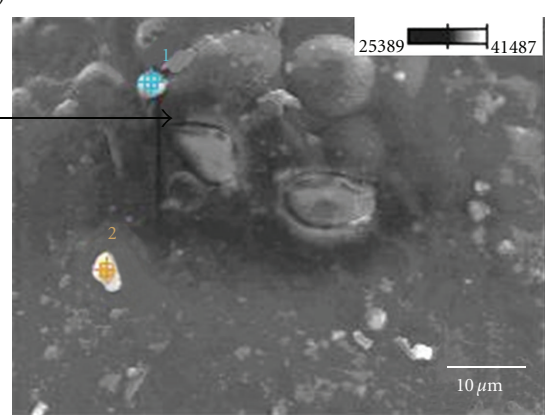

(f)

Full-scale counts: 10265

200M(1)_pt1

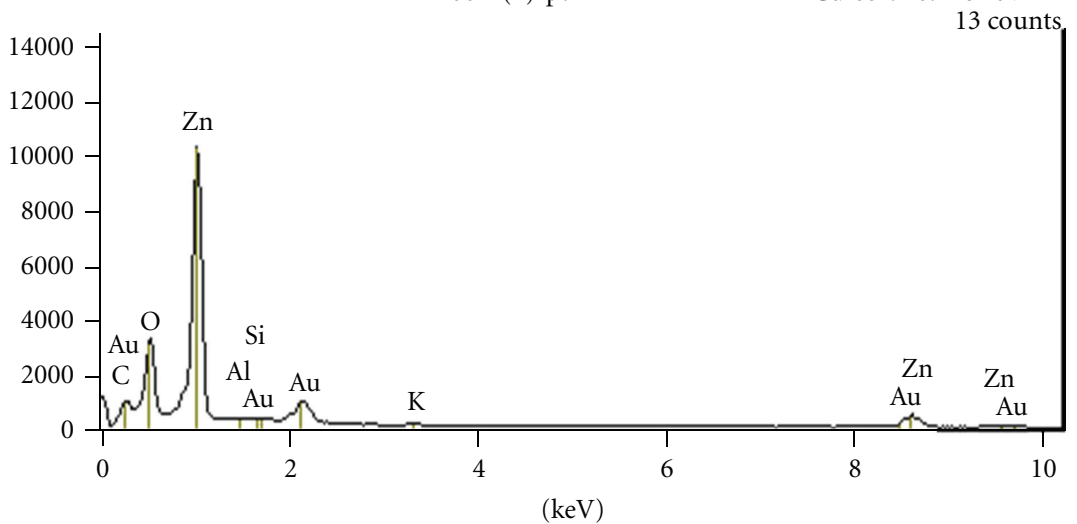

(g)

Figure 6: Scanning electron micrographs of roots of mung (Vigna radiata) (a) control, (b) at 20 ppm with EDAX (c) and (d) and (e) at 2000 ppm with EDAX (f) and (g) of nano-ZnO treatment. The energy dispersive spectroscopy shows the Zn peaks obtained from points indicated by the arrow. 


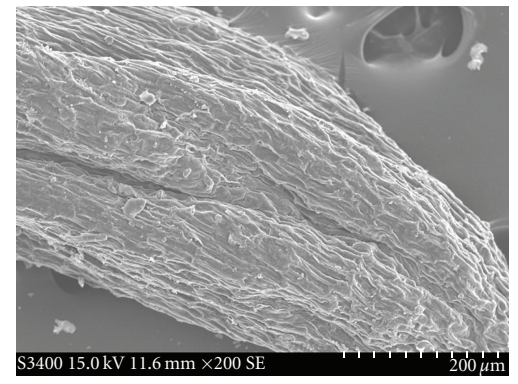

(a)

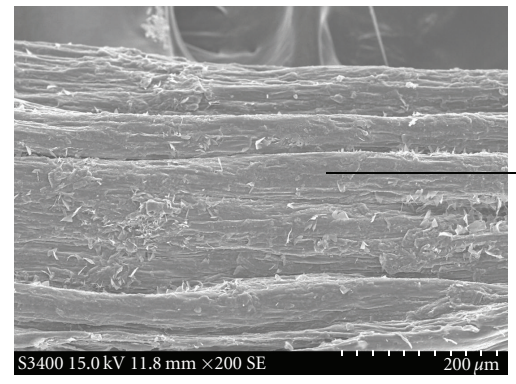

(b)

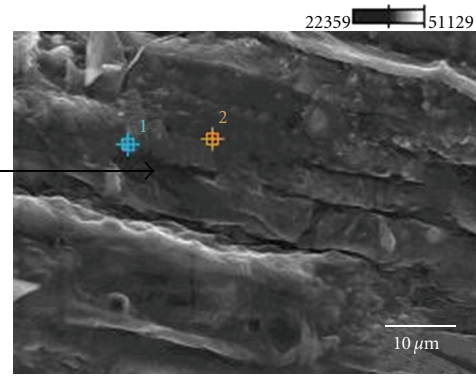

(c)

Full-scale counts: 1880

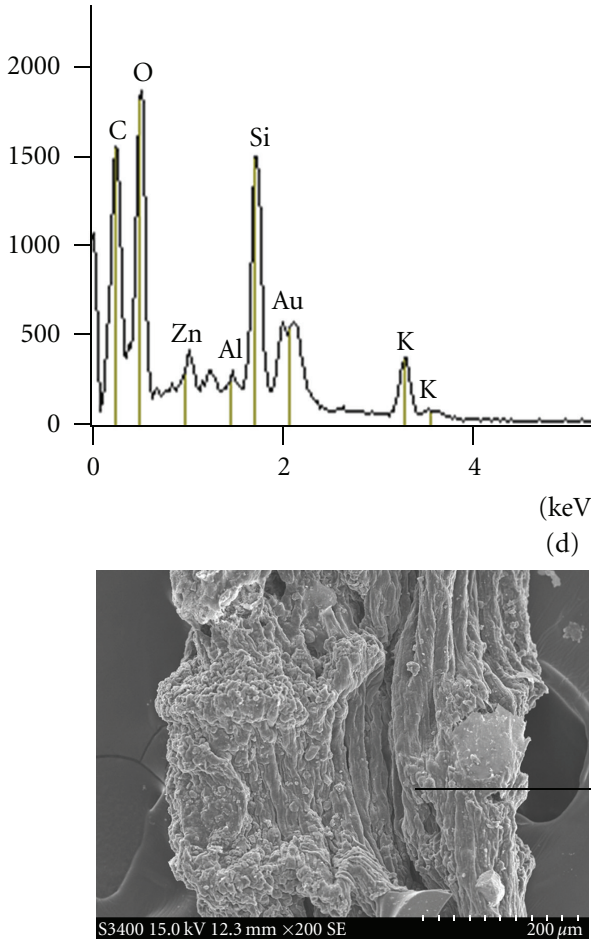

(e)

Full-scale counts: 1103

2000G_pt2

Cursor: $10.216 \mathrm{keV}$

11 counts

)

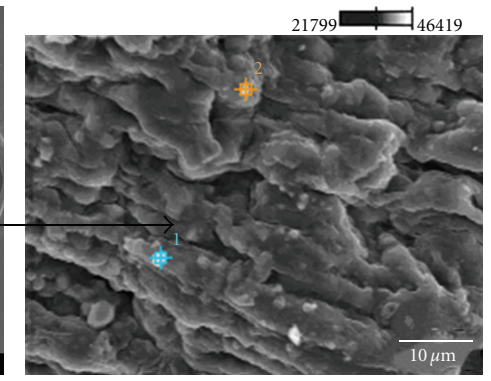

(f)

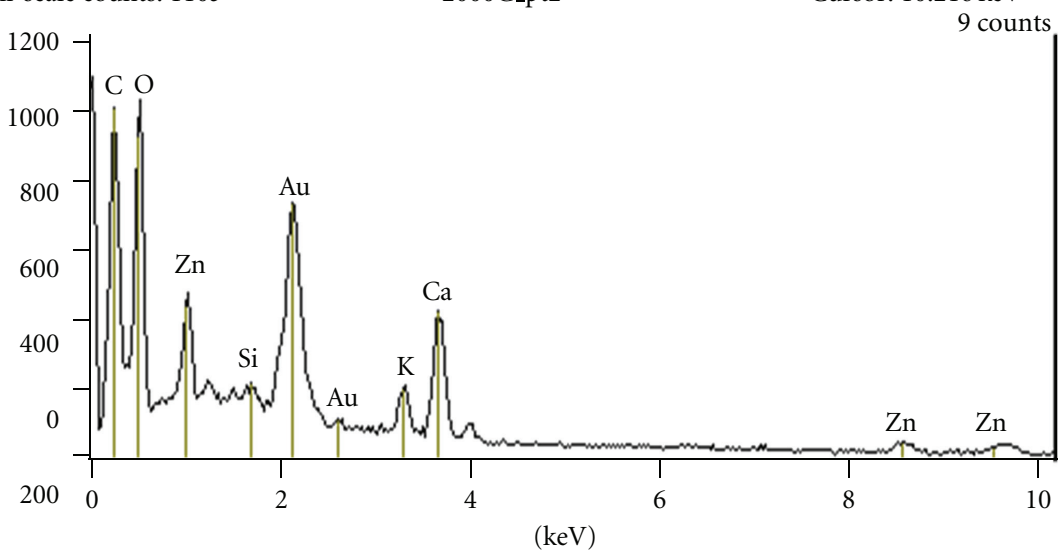

(g)

FIGURE 7: Scanning electron micrographs of roots of gram (Cicer arietinum) (a) control, (b) at 1 ppm with EDAX (c) and (d) and (e) at 2000 ppm with EDAX (f) and (g) of nano-ZnO treatment. The energy dispersive spectroscopy shows the Zn peaks obtained from points indicated by the arrow. 


\section{Conclusion}

The presence of $\mathrm{ZnO}$ nanoparticles affects the growth of mung and gram seedlings at different concentrations. The maximum effect was found at $20 \mathrm{ppm}$ for mung (Vigna radiata) and $1 \mathrm{ppm}$ for gram (Cicer arietinum) seedlings. Beyond this concentration, the growth was inhibited. The statistically determined $P$ value for root and shoot growth at optimum concentration and at highest concentration was found to be less than $5 \%$. The effective growth at certain optimum concentration and inhibited growth beyond this concentration may be attributed to the accumulation and uptake of nano-ZnO particle by the roots. It was found that the accumulation and uptake of nanoparticles was dependent on the exposure concentrations.

\section{Acknowledgment}

The authors acknowledge Indian Council of Agriculture Research (ICAR) for the financial support under National Agricultural Innovative Project (NAIP) and Indian Institute of Technology Bombay for providing Analytical Characterization Techniques.

\section{References}

[1] L. Zheng, F. Hong, S. Lu, and C. Liu, "Effect of nano- $\mathrm{TiO}_{2}$ on strength of naturally aged seeds and growth of spinach," Biological Trace Element Research, vol. 104, no. 1, pp. 83-91, 2005.

[2] V. Shah and I. Belozerova, "Influence of metal nanoparticles on the soil microbial community and germination of lettuce seeds," Water, Air, and Soil Pollution, vol. 197, no. 1-4, pp. 143-148, 2009.

[3] W.-X. Zhang, "Nanoscale iron particles for environmental remediation: an overview," Journal of Nanoparticle Research, vol. 5, no. 3-4, pp. 323-332, 2003.

[4] D. W. Galbraith, "Nanobiotechnology: silica breaks through in plants," Nature Nanotechnology, vol. 2, no. 5, pp. 272-273, 2007.

[5] H.-J. Park, S. H. Kim, H. J. Kim, and S.-H. Choi, "A new composition of nanosized silica-silver for control of various plant diseases," Plant Pathology, vol. 22, no. 3, pp. 295-302, 2007.

[6] L. Yang and D. J. Watts, "Particle surface characteristics may play an important role in phytotoxicity of alumina nanoparticles," Toxicology Letters, vol. 158, no. 2, pp. 122-132, 2005.

[7] W. M. Lee, Y. J. An, H. Yoon, and H. S. Kweon, "Toxicity and bioavailability of copper nanoparticles to the terrestrial plants mung bean (Phaseolus radiatus) and wheat (Triticum aestivum): plant agar test for water-insoluble nanoparticles," Environmental Toxicology and Chemistry, vol. 27, no. 9, pp. 1915-1921, 2008.

[8] C. M. Lu, C. Y. Zhang, J. Q. Wen, G. R. Wu, and M. X. Tao, "Research on the effect of nanometer materials on germination and growth enhancement of Glycine max and its mechanism," Soybean Science, vol. 21, no. 3, pp. 68-172, 2002.

[9] F. Hong, J. Zhou, C. Liu et al., "Effect of $\mathrm{Nano}^{-\mathrm{TiO}_{2}}$ on photochemical reaction of chloroplasts of spinach," Biological Trace Element Research, vol. 105, no. 1-3, pp. 269-279, 2005.

[10] F. Hong, F. Yang, C. Liu et al., "Influences of nano- $\mathrm{TiO}_{2}$ on the chloroplast aging of spinach under light," Biological Trace Element Research, vol. 104, no. 3, pp. 249-260, 2005.
[11] F. Yang, F. Hong, W. You et al., "Influences of nano-anatase $\mathrm{TiO}_{2}$ on the nitrogen metabolism of growing spinach," Biological Trace Element Research, vol. 110, no. 2, pp. 179-190, 2006.

[12] J. E. Cañas, M. Long, S. Nations et al., "Effects of functionalized and nonfunctionalized single-walled carbon nanotubes on root elongation of select crop species," Environmental Toxicology and Chemistry, vol. 27, no. 9, pp. 1922-1931, 2008.

[13] D. Lin and B. Xing, "Phytotoxicity of nanoparticles: inhibition of seed germination and root growth," Environmental Pollution, vol. 150, no. 2, pp. 243-250, 2007.

[14] P. González-Melendi, R. Fernández-Pacheco, M. J. Coronado et al., "Nanoparticles as smart treatment-delivery systems in plants: assessment of different techniques of microscopy for their visualization in plant tissues," Annals of Botany, vol. 101, no. 1, pp. 187-195, 2008. 

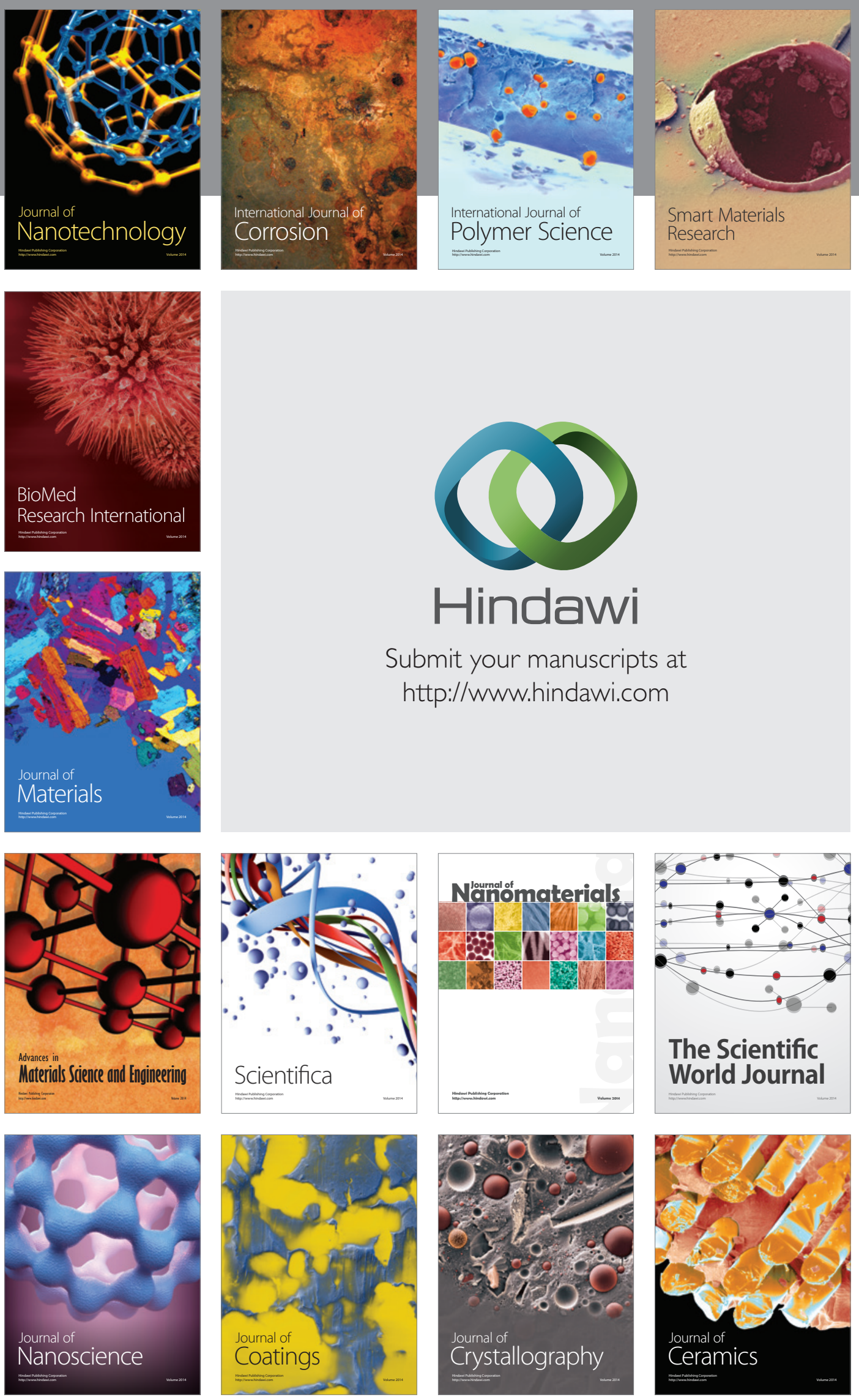

The Scientific World Journal

Submit your manuscripts at

http://www.hindawi.com

\section{World Journal}

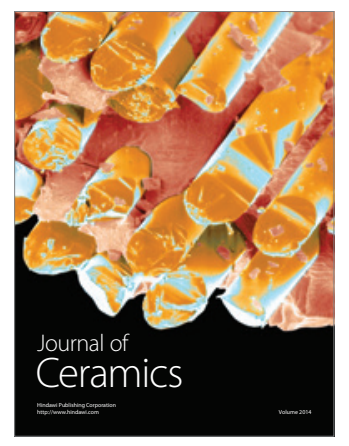

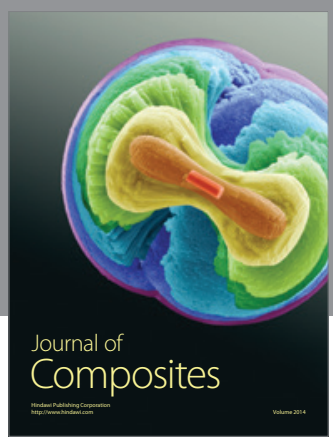
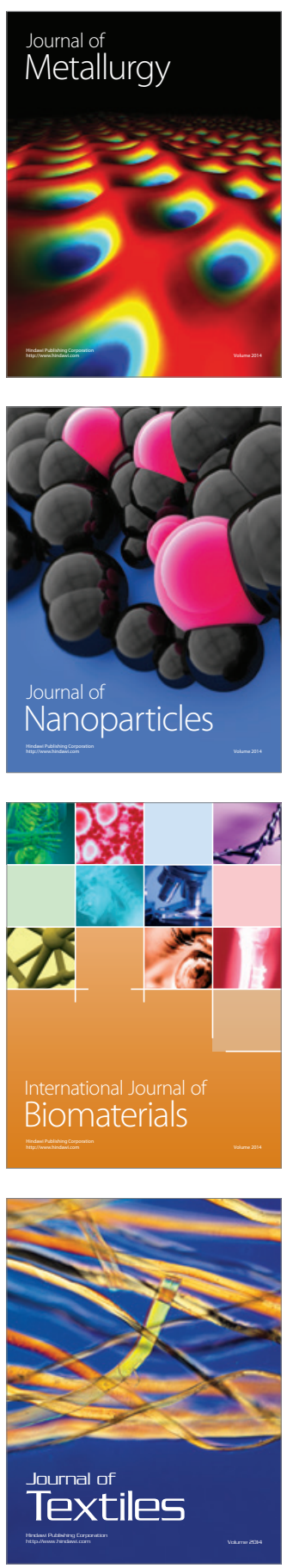